\title{
Incidental catheter-associated upper extremity deep venous thrombosis detected by point-of- care ultrasound
}

\author{
Nilam J. Soni, ${ }^{1,2}$ Minh-Phuong T Le, ${ }^{1}$ Maria Inez Velez, ${ }^{1}$ Kevin C. Proud (i) ${ }^{1,2}$
}

'Department of Medicine, University of Texas Health San Antonio, San Antonio, Texas, USA

${ }^{2}$ Medicine Service, South Texas Veterans Health Care System, San Antonio, Texas, USA

\section{Correspondence to}

Dr Nilam J. Soni;

sonin@uthscsa.edu

Accepted 10 August 2021

\section{DESCRIPTION}

A woman in her 50s presented for surveillance bronchoscopy 3 months after bilateral lung transplantation for alpha-1 antitrypsin deficiency. She was asymptomatic and her physical examination was unremarkable. While performing a prebronchoscopy pleural ultrasound examination to assess for lung sliding, a large mobile thrombus was incidentally found in the proximal right axillary vein below the clavicle. The thrombus was adhered to a venous valve and wavered with each venous pulsation (figure $1 \mathrm{~A}$, video 1 ). Further evaluation of the right upper extremity veins revealed complete thrombosis of the basilic vein where a peripherally inserted central venous catheter (PICC) had been previously placed. The lung transplantation team initiated subcutaneous enoxaparin and bridged her to warfarin as an outpatient. She returned for her next surveillance bronchoscopy 4 weeks later, and the same team performed a repeat ultrasound examination over the same venous valve, which showed complete resolution of the thrombus (figure $1 \mathrm{~B}$, video 2).

Upper extremity deep venous thrombosis (UEDVT) accounts for 5\%-10\% of all deep venous thromboses (DVTs). ${ }^{12}$ The incidence of venous thromboembolism (VTE) is high among lung transplant patients, with a reported incidence of $6 \%-9 \%$ in retrospective studies. ${ }^{34}$ Postmortem examination of lung and heart-lung transplant patients found $27 \%$ had evidence of pulmonary embolism. ${ }^{5}$ VTE among lung transplant patients is associated with
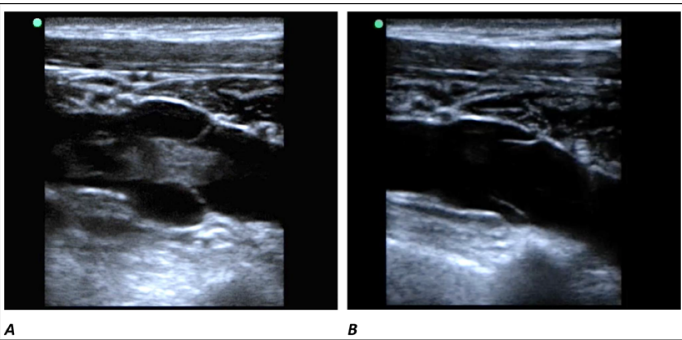

Figure 1 Incidental upper extremity deep venous thrombosis. (A) A mobile upper extremity deep vein thrombus adherent to a venous valve was detected incidentally in the proximal right axillary vein during a prebronchoscopy lung ultrasound examination. (B) Complete resolution of the deep venous thrombosis is seen over the same valve after 4 weeks of anticoagulation.

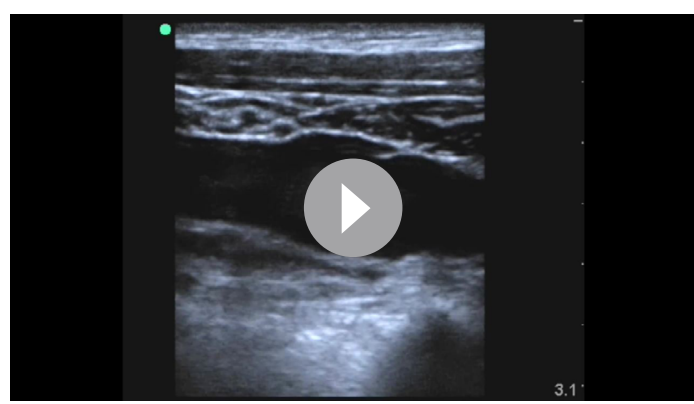

Video 1 Incidental upper extremity deep venous thrombosis. An upper extremity deep vein thrombus adherent to a venous valve is seen wavering in the lumen of the proximal right axillary vein.

increased length of stay, costs of hospitalisation and in-hospital mortality. ${ }^{3}$

Approximately $50 \%$ of UEDVTs are caused by central venous catheters (CVCs), ${ }^{12}$ and $30 \%$ of patients with indwelling venous catheters can have asymptomatic UEDVTs. ${ }^{6}$ PICC has a 2.6 -fold increased risk of thrombosis compared with CVC. ${ }^{7}$ Other important risk factors for UEDVT include malignancy, recent surgery or trauma, pregnancy, hormone therapy and thrombophilic disorders. UEDVT occurs most frequently in the subclavian, axillary, jugular, brachial and brachiocephalic veins but can involve more distal veins. ${ }^{1}$

Point-of-care ultrasound (POCUS) is a wellvalidated tool for detection of lower extremity DVTs, with a sensitivity of $86 \%-96 \%$ and a specificity $>96 \% .{ }^{89}$ Conversely, data on the ability of POCUS to detect UEDVT are limited. One study comparing POCUS versus radiology-performed ultrasound examinations found no discordance for

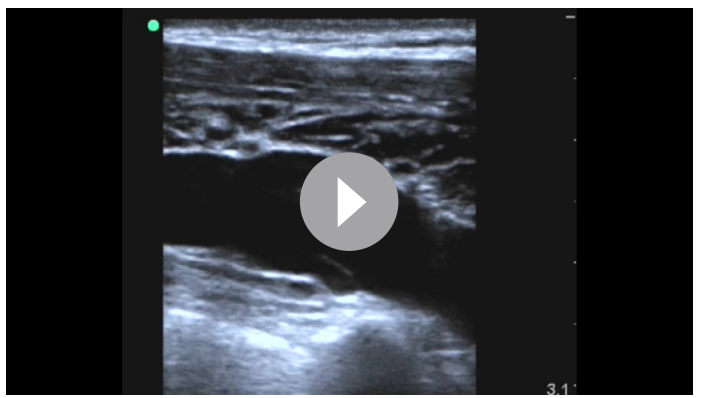

Video 2 Resolution of deep venous thrombosis. After 4 weeks of anticoagulation, complete resolution of the upper extremity deep venous thrombosis is seen over the same venous valve. 
nine UEDVTs that were detected. ${ }^{10}$ In children, POCUS demonstrated 28\% sensitivity and $91 \%$ specificity for identifying catheter-associated thrombosis in both upper and lower extremities. Most discordant findings involved the subclavian vein, likely due to difficulty performing venous compression with an ultrasound probe at this site. ${ }^{11}$

Evidence for specific treatment of UEDVT is limited. No large randomised controlled trials have been published to date. ${ }^{12}$ Despite this, general consensus exists to treat UEDVT in the axillary and more proximal veins with anticoagulation therapy for at least 3 months. ${ }^{121213}$ Current evidence suggests that anticoagulation using warfarin, low-molecular-weight heparin or direct oral anticoagulants (specifically rivaroxaban, apixaban, edoxaban or dabigatran) is effective and safe, with the latter two options preferred in cancer-associated UEDVTs. ${ }^{12}$ In catheterassociated thrombosis, anticoagulation therapy should be initiated despite line removal and continued for at least 3 months after removal. Thus, a thrombosed catheter can remain in place if indicated with concurrent anticoagulation treatment. ${ }^{113}$

In conclusion, catheter-associated DVTs are common and may be incidentally detected by POCUS. Controversy exists about the best management strategy for catheter-associated UEDVTs due to the lack of high-quality evidence.

Learning points

- Catheter-associated venous thrombosis is common and likely can be detected accurately by point-of-care ultrasound when performed by a trained provider.

- Current guidelines recommend treating thrombosis of the axillary and more proximal veins with anticoagulation therapy for at least 3 months.

- Controversy exists about the best management strategy for catheter-associated venous thrombosis, but general consensus is to treat these patients with anticoagulation.

Contributors NS, MIV and KCP contributed to the conceptualisation of the case report. NS, MIV and KCP collected the patient's data. NS, M-PTL, KCP and MIV interpreted the data. NS, M-PTL, MIV and KCP drafted the manuscript, made critical revisions and approved the final manuscript. NS, M-PTL, MIV and KCP are accountable for all aspects of the manuscript.

Funding The authors have not declared a specific grant for this research from any funding agency in the public, commercial or not-for-profit sectors.

Competing interests None declared.

Patient consent for publication Next of kin consent obtained.

Provenance and peer review Not commissioned; externally peer reviewed.

\section{ORCID iD}

Kevin C. Proud http://orcid.org/0000-0003-3480-4069

\section{REFERENCES}

1 Bosch FTM, Nisio MD, Büller HR, et al. Diagnostic and therapeutic management of upper extremity deep vein thrombosis. J Clin Med 2020;9:2069.

2 Woller SC, Stevens SM, Johnson SA, et al. Apixaban for routine management of upper extremity deep venous thrombosis (ARM-DVT): methods of a prospective single-arm management study. Res Pract Thromb Haemost 2019:3:340-8.

3 Aboagye JK, Hayanga JWA, Lau BD, et al. Venous thromboembolism in patients hospitalized for lung transplantation. Ann Thorac Surg 2018;105:1071-6.

4 Izbicki G, Bairey 0, Shitrit D, et al. Increased thromboembolic events after lung transplantation. Chest 2006;129:412-6.

5 Burns KEA, lacono AT. Pulmonary embolism on postmortem examination: an under-recognized complication in lung-transplant recipients? Transplantation 2004:77:692-8.

6 Van Rooden CJ, Rosendaal FR, Meinders AE, et al. The contribution of factor V Leiden and prothrombin G20210A mutation to the risk of central venous catheter-related thrombosis. Haematologica 2004;89:201-6.

7 Chopra V, Anand S, Hickner A, et al. Risk of venous thromboembolism associated with peripherally inserted central catheters: a systematic review and meta-analysis. Lancet 2013;382:311-25

8 Kory PD, Pellecchia CM, Shiloh AL, et al. Accuracy of ultrasonography performed by critical care physicians for the diagnosis of DVT. Chest 2011;139:538-42.

9 Pomero F, Dentali F, Borretta V, et al. Accuracy of emergency physician-performed ultrasonography in the diagnosis of deep-vein thrombosis: a systematic review and meta-analysis. Thromb Haemost 2013;109:137-45.

10 Kapoor S, Chand S, Dieiev V, et al. Thromboembolic events and role of point of care ultrasound in hospitalized Covid-19 patients needing intensive care unit admission. J Intensive Care Med 2020;885066620964392:885066620964392.

11 Li S, Silva CT, Brudnicki AR, et al. Diagnostic accuracy of point-of-care ultrasound for catheter-related thrombosis in children. Pediatr Radiol 2016;46:219-28.

12 Kearon C, AkI EA, Ornelas J, et al. Antithrombotic therapy for VTe disease: chest guideline and expert panel report. Chest 2016;149:315-52.

13 Guyatt GH, AkI EA, Crowther M, et al. Executive summary: antithrombotic therapy and prevention of thrombosis, 9th ED: American College of chest physicians evidencebased clinical practice guidelines. Chest 2012;141:7s-47.

Copyright 2021 BMJ Publishing Group. All rights reserved. For permission to reuse any of this content visit

https://www.bmi.com/company/products-services/rights-and-licensing/permissions/

BMJ Case Report Fellows may re-use this article for personal use and teaching without any further permission.

Become a Fellow of BMJ Case Reports today and you can:

- Submit as many cases as you like

- Enjoy fast sympathetic peer review and rapid publication of accepted articles

- Access all the published articles

- Re-use any of the published material for personal use and teaching without further permission

Customer Service

If you have any further queries about your subscription, please contact our customer services team on +44 (0) 2071111105 or via email at support@bmj.com.

Visit casereports.bmj.com for more articles like this and to become a Fellow 